\title{
Viable access to the triplet excited state in peryleneimide based palladium complex ${ }^{\S}$
}

\author{
ABBEY M PHILIP, EBIN SEBASTIAN, GOPIKA GOPAN, REMYA RAMAKRISHNAN and \\ MAHESH HARIHARAN*(D)
}

School of Chemistry, Indian Institute of Science Education and Research Thiruvananthapuram (IISER-TVM), Maruthamala P.O., Vithura, Thiruvananthapuram, Kerala 695 551, India

E-mail: mahesh@iisertvm.ac.in

MS received 9 June 2018; revised 30 July 2018; accepted 1 August 2018; published online 26 September 2018

\begin{abstract}
Triplet excited state in organic chromophores is ubiquitously significant owing to its utility in light harvesting and photovoltaic device applications. Herein, we report the enhancement in the triplet character of an innately triplet deficient peryleneimide chromophore via incorporation of a heavy atom. Palladium incorporated perylenemonoimide (PMI-Pd) was synthesized via oxidative addition of $\mathrm{PMI}-\mathrm{Br}$ into $\mathrm{Pd}(0)$ under inert experimental conditions. The structural sanctity of the PMI-Pd and the model derivative PMI was characterized via single crystal X-ray diffraction and the close-packing was examined employing Hirshfeld surface analysis. The steady-state spectroscopic measurements of PMI-Pd in chloroform reveal an apparent perturbation in the UV-Vis absorption, fluorescence emission and lifetime characteristics. A much higher perturbation is observed in the ultrafast photoexcited processes of PMI-Pd in chloroform as envisaged via nanosecond transient absorption (nTA) measurements. The nTA measurements of PMI-Pd in chloroform reveal a significant enhancement in the triplet character of PMI-Pd as compared to the model derivative PMI. Spin-orbit coupling (SOC) mediated triplet enhancement in PMI-Pd suggest heavy atom incorporation as a viable route for accessing the triplet excited states in triplet deficient aromatic chromophores. SOC mediated triplet enhancement in innately triplet deficient organic chromophores can revive the utility of these materials for novel photovoltaic and energy storage applications.
\end{abstract}

Keywords. Perylenemonoimide; palladium complex; triplet; spin-orbit coupling.

\section{Introduction}

Peryleneimide (PI) family of chromophores have been long-known as a lightfast vat dye and have been explored for its versatile optical properties. ${ }^{1,2}$ Owing to its remarkable fluorescence characteristics and high photo, thermal and chemical stability, PI's have gained immense significance in emerging optical and electronic device applications. ${ }^{3-5}$ Additionally, the significant electron affinity of PI fortifies its utility as a nonfullerene acceptor while exploring fundamental aspects of light-harvesting in artificial donor-acceptor (D-A) systems, ${ }^{6-8}$ its application in organic bulk heterojunction solar cells $\mathrm{s}^{9,10}$ and incipient energy storage application. ${ }^{11-13}$ However, PI vitiates its intense fluorescence character upon self-assembly (viz. solidstate) and is inherently triplet deficient. ${ }^{14}$ Long-lived triplet character of a chromophore can be a vital factor controlling the exciton migration and the efficiencies of the D-A blends used for organic photovoltaics. ${ }^{15,16}$ To date, the access to the triplet excited state in organic chromophores has been reported via bimolecular triplet sensitization, ${ }^{17}$ spin-orbit coupling mediated heavy-atom effect, ${ }^{18-21}$ singlet fission ${ }^{14,22,23}$ and

\footnotetext{
*For correspondence

$\S$ Dedicated to Professor M V George on the occasion of his $90^{\text {th }}$

Birth Anniversary.
}

Electronic supplementary material: The online version of this article (https://doi.org/10.1007/s12039-018-1537-x) contains supplementary material, which is available to authorized users. 
charge-recombination of the photoinduced radical-ion pair intermediates. ${ }^{24-26}$ Though the above-mentioned methods can populate the triplet state, they are prone to annihilation and the generation of efficient long-lived triplet excited-state in innately triplet deficient chromophores remains a highly investigated subject.

Our continual efforts in exploring the photoexcited state properties of organic crystalline ${ }^{27-29} /$ nonplanar DA assemblies, ${ }^{30-32}$ and core-twisted ${ }^{14,33}$ organic chromophores motivated us to investigate the effect of a heavy-atom on the photoexcited state properties of perylenemonoimide (PMI). The synthesis of the heavyatom appended PMI (PMI-Pd) was carried via oxidative addition of $\mathrm{PMI}-\mathrm{Br}$ to $\mathrm{Pd}\left(\mathrm{PPh}_{3}\right)_{4}$ under inert experimental conditions. The structure of PMI-Pd was further characterized via nuclear magnetic resonance (NMR), high-resolution mass spectrometry (HRMS) and single crystal X-ray diffraction analysis. The consequence of the direct attachment of the $-\mathrm{Pd}\left(\mathrm{PPh}_{3}\right)_{2} \mathrm{Br}$ to the PMI core was evident from the stead-state spectroscopic and time-resolved lifetime analysis. The UV-Vis absorption and fluorescence emission spectra of PMI-Pd in chloroform reveal an apparent red-shift as compared to the model derivative. The lifetime analysis of PMI-Pd in chloroform also displayed a similar perturbation as compared to the model derivative PMI. The effect of the heavy-atom $(\mathrm{Pd})$ substitution in PMI was further explored employing the time-resolved spectroscopic analysis. The femtosecond transient absorption (fTA) measurements of both PMI-Pd and the model derivative PMI reveal the presence of the singlet excited state at 630-640 $\mathrm{nm}$. The nanosecond transient absorption (nTA) measurements of PMI-Pd and PMI reveal the presence of the triplet excited state; however, the singletto-triplet transition was not perceived. Interestingly, the triplet formation in PMI-Pd was found to be higher $(0.58 \pm 0.01)$ as compared to the model derivative PMI $(0.08 \pm 0.005)$ leading to the quenching of the fluorescence in PMI-Pd. A similar heavy-atom (Pd) substituted PDI derivative displayed a high fluorescence character and a comparatively low yet significant heavy-atom effect upon direct attachment of Pd to the PDI core. ${ }^{6}$ The quenched fluorescence in PMI-Pd and the higher yield of triplet formation suggest the combined effect of the heavy atoms ( $\mathrm{Pd}$ and the adjacent $\mathrm{Br}$ ) mediating the spinorbit coupling in PMI-Pd. Thus, the spin-orbit coupling mediated heavy-atom can allow a viable access route to achieve triplet character in integrally triplet deficient aromatic chromophores. Triplet enhancement in PMI$\mathrm{Pd}$ as compared to the triplet deficient PMI chromophore can renovate the utility of such chromophoric systems for innovative light harvesting and energy-related applications.

\section{Experimental}

\subsection{Materials and methods}

All chemicals were obtained from commercial suppliers and used as received without further purification. All reactions were carried out in oven-dried glassware prior to use and wherever necessary, were performed under dry nitrogen in dried, anhydrous solvents using standard gastight syringes, cannulae, and septa. Solvents were dried and distilled by standard laboratory purification techniques. TLC analysis was performed on precoated aluminium plates of silica gel 60 F254 plates $(0.25 \mathrm{~mm}$, Merck) and developed TLC plates were visualized under short and long wavelength UV lamps. Flash column chromatography was performed using silica gel of 200-400 mesh employing a solvent polarity correlated with the TLC mobility observed for the substance of interest. Yields refer to chromatographically and spectroscopically homogenous substances. Melting points were obtained using a capillary melting point apparatus and are uncorrected. IR spectra were recorded on a Shimadzu IRPrestige-21 FTIR spectrometer as $\mathrm{KBr}$ pellets. ${ }^{1} \mathrm{H}$ and ${ }^{13} \mathrm{C}$ NMR spectra were measured on a $500 \mathrm{MHz}$ Bruker Avance DPX spectrometer. Internal standard used for ${ }^{1} \mathrm{H}$ and ${ }^{13} \mathrm{C}$ NMR is 1,1,1,1-tetramethyl silane (TMS). High-resolution mass spectra (HRMS) were recorded on Thermo Scientific Q Exactive mass spectrometer using electrospray ionization (ESI, positive mode) technique.

2.1a Steady-state spectroscopy: Photophysical measurements of the derivatives were carried out in a cuvette of $3 \mathrm{~mm}$ path length unless otherwise mentioned. Absorption and emission spectra were recorded on Shimadzu UV-3600 UV-VIS-NIR and Horiba Jobin Yvon Fluorolog spectrometers respectively. Solution-state relative quantum yield measurements were performed using Rhodamine $6 \mathrm{G}$ as the standard $\left(\lambda_{\mathrm{ex}}=488 \mathrm{~nm}\right.$, reported quantum yield $\left.\Phi_{\mathrm{f}}=0.94\right) .{ }^{34}$ Lifetime measurements were carried out in an IBH picosecond time-correlated single photon counting (TCSPC) system. The fluorescence decay profiles were de-convoluted using IBH data station software (DAS 6.3), and fitted with exponential decay, minimizing the $\chi^{2}$ values.

Solution-state fluorescence quantum yields of PMI and PMI-Pd derivatives were calculated by relative quantum yield method as follows,

$\Phi_{\mathrm{s}}=\Phi_{\mathrm{ref}}\left(\frac{\mathrm{I}_{\mathrm{s}}}{\mathrm{I}_{\mathrm{ref}}}\right)\left(\frac{\mathrm{OD}_{\mathrm{ref}}}{\mathrm{OD}_{\mathrm{s}}}\right)\left(\frac{\mathrm{n}_{\mathrm{s}}}{\mathrm{n}_{\mathrm{ref}}}\right)^{2}$

wherein, $\Phi_{\mathrm{s}}$ and $\Phi_{\text {ref }}$ are the quantum yields of sample and reference respectively, $\mathrm{I}_{\mathrm{S}}$ and $\mathrm{I}_{\text {ref }}$ are the area under the emission spectrum for sample and reference respectively. $\mathrm{OD}_{\mathrm{s}}$ and $\mathrm{OD}_{\text {ref }}$ are the absorbances of the sample and reference respectively at the excitation wavelength. $\mathrm{n}_{\mathrm{s}}$ and $\mathrm{n}_{\text {ref }}$ are the refractive index of the solvent in which sample and reference are taken. 
Table 1. Crystallographic data and refinement parameters for crystalline PMI-Pd.

\begin{tabular}{|c|c|}
\hline Parameters & PMI-Pd \\
\hline Formula & $\mathrm{C}_{70} \mathrm{H}_{56} \mathrm{BrNO}_{2} \mathrm{P}_{2} \mathrm{Pd}$ \\
\hline Formula wt & 1191.40 \\
\hline Colour, shape & Red \\
\hline Dimens, mm & $0.24 \times 0.1 \times 0.08$ \\
\hline Crystal system & Triclinic \\
\hline Space group, Z & $P-1$ \\
\hline $\mathrm{a}, \AA$ & 13.1460 \\
\hline $\mathrm{b}, \AA$ & 14.7260 \\
\hline $\mathrm{c}, \AA$ & 19.047 \\
\hline$\alpha, \operatorname{deg}$ & 110.927 \\
\hline$\beta$, deg & 91.113 \\
\hline$\gamma, \operatorname{deg}$ & 102.763 \\
\hline $\mathrm{V}, \AA^{3}$ & 3339.3 \\
\hline Temp, K & $296(2)$ \\
\hline $\mathrm{d}_{\text {calcd }}, \mathrm{mg} / \mathrm{m}^{3}$ & 1.185 \\
\hline No. of reflections collected & 50862 \\
\hline No. of unique reflections & 11666 \\
\hline $2 \theta_{\max }, \operatorname{deg}$ & 50 \\
\hline No. of parameters & 694 \\
\hline $\mathrm{R} 1$, wR2 $(\mathrm{I}>2 \mathrm{~s}(\mathrm{I}))$ & $0.0915,0.2737$ \\
\hline R1, wR2 (all data) & $0.1352,0.3227$ \\
\hline Goodness of fit & 1.096 \\
\hline CCDC number & 1845450 \\
\hline
\end{tabular}

The crystal structure of PMI is available on CCDC with a deposition number 900321. ${ }^{27}$

2.1b X-ray crystallography: Single crystal of PMI-Pd was obtained by slow evaporation of solvent from $n$-hexane: chloroform (1:1) homogenous mixture at room temperature. High-quality specimens of approximate $0.24 \times 0.1 \times$ $0.08 \mathrm{~mm}^{3}$ dimension were selected for the X-ray diffraction experiments. Crystallographic data collected for PMI-Pd is presented in Table 1. A single crystal was mounted using oil (Infineum V8512) on a glass fibre. All measurements were made on a CCD area detector with graphite monochromated Mo $\mathrm{K}_{\alpha}$ radiation. The data were collected using a Bruker APEXII detector and processed using APEX2 from Bruker. The structure was solved by a direct method and expanded using Fourier technique. The non-hydrogen atoms were refined anisotropically. Hydrogen atoms were included in idealized positions, but not refined. Their positions were constrained relative to their parent atom using the appropriate HFIX command in SHELX-97. ${ }^{35}$ All the programs used during the crystal structure analysis are incorporated in the WINGX software. ${ }^{36}$ The full validation of CIF and structure factor of PMI-Pd was performed using the checkCIF utility and found to be free of major alert levels. 3D structure visualization and the exploration of the crystal packing of PMI-Pd was carried out using Mercury 3.5.1. ${ }^{37,38}$

2.1c Femtosecond transient absorption (fTA) technique: Spectra-Physics Tsunami Oscillator $(80 \mathrm{MHz}$, $800 \mathrm{~nm}$ ) was used as a seed for a Spectra-Physics Spitfire
Regenerative Amplifier (1 kHz, $4 \mathrm{~mJ})$. A fraction of the amplified output was used to generate $400 \mathrm{~nm}$ pump pulse. Residual $800 \mathrm{~nm}$ pulse was sent through a delay line inside an Excipro pump-probe spectrometer from CDP systems. A rotating $\mathrm{CaF}_{2}$ plate ( $2 \mathrm{~mm}$ thickness) was used to generate a continuum of white light from the delayed $800 \mathrm{~nm}$ pulses. The continuum of white light was split into two and the streams were used as a probe and reference pulses. Transient absorption spectra were recorded using a dual diode array detector having a $200 \mathrm{~nm}$ detection window with an optical delay of 1.6 fs. Sample solutions were prepared in a rotating sample cell with $4 \mathrm{~mm}$ path length. IRF was determined by solvent (10\% benzene in methanol) two-photon absorption and was found to be approximately $110 \mathrm{fs}$ at about $530 \mathrm{~nm}$. Energy per pulse incident on the sample is attenuated employing $80 \%$ neutral density filter when required. fTA measurements of PMI and PMI-Pd in $\mathrm{CHCl}_{3}$ were excited at $400 \mathrm{~nm}, 200 \mathrm{~nJ}$, $\approx 110$ fs pulses, to moderate singlet-singlet annihilation that occurs often in multichromophoric assemblies. ${ }^{39}$ The observed kinetic components are laser intensity independent, ruling out the assignment of kinetic components to singletsinglet annihilation. ${ }^{39}$

2.1d Nanosecond transient absorption (nTA) measurements: Nanosecond laser flash photolysis experiments of the argon-purged solutions of PMI and PMI-Pd were carried out in an Applied Photophysics Model LKS60 laser kinetic spectrometer using the second harmonic $\left(\lambda_{\mathrm{ex}}=355 \mathrm{~nm}\right.$, pulse duration $\left.\approx 7 \mathrm{~ns}\right)$ of a Quanta Ray INDI-40-10 series pulsed Nd: YAG laser as the excitation source. Triplet states of PMI and PMI-Pd in chloroform were confirmed performing the experiments with oxygen purged solutions. Triplet quantum yields upon direct photoexcitation $(355 \mathrm{~nm})$ were determined using $[\mathrm{Ru}(\mathrm{bpy})] \mathrm{Cl}_{2}$ in methanol as standard with nonsaturating laser intensities. An equal volume of $0.2 \mathrm{mM}$ solution of $\beta$-carotene was added to optically matched solutions of reference and the sample. The equation for the triplet quantum yield is given by, ${ }^{40}$

$\Phi_{T}^{s}=\Phi_{T}^{R e f} \times \frac{\Delta A^{s}}{\Delta A^{R e f}} \times \frac{k_{o b s}^{s}}{k_{o b s}^{s}-k_{0}^{s}} \times \frac{k_{o b s}^{R e f}-k_{0}^{R e f}}{k_{o b s}^{R e f}}$

Where, $\Phi_{T}^{s}$ and $\Phi_{T}^{R e f}$ denote the triplet quantum yield of the sample and reference respectively; $\Delta A^{s}$ and $\Delta A^{R e f}$ are transient absorption intensity of $\beta$-carotene in sample and reference respectively; $k_{o b s}^{s}$ and $k_{0}^{s}$ are decay rate of sample transient species before and after the addition of $\beta$-carotene. $k_{o b s}^{R e f}$ and $k_{0}^{R e f}$ are the decay rate of reference transient species before and after the addition of $\beta$-carotene.

The triplet formation rates in the two derivatives PMI and PMI-Pd were not perceived as the fTA experiments were limited to $2.7-3.5 \mathrm{~ns}$, whereas the nTA measurements provide the signals from $10 \mathrm{~ns}$ onwards only. Lack of clear singlet-triplet (S-T) transition in the femtosecond (fTA) and nanosecond transient absorption (nTA) measurements suggest the triplet formation is slow and may form in 3.5-10 ns window, which we are not able to perceive in our current experimental setup. 


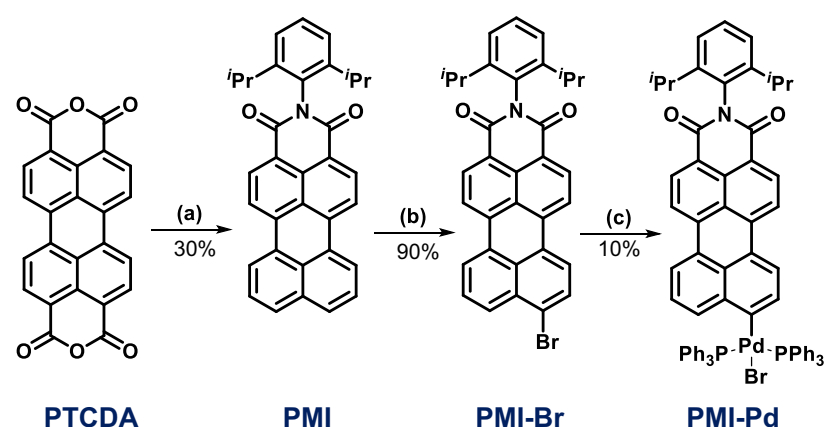

Scheme 1. Synthesis scheme for PMI-Pd. (a) 2,6-diisopropylamine, imidazole, $\mathrm{Zn}(\mathrm{OAc})_{2}, \mathrm{H}_{2} \mathrm{O}, 190^{\circ} \mathrm{C}, 24 \mathrm{~h}$; (b) $\mathrm{Br}_{2}, \mathrm{I}_{2}$, Glacial acetic acid, RT, 6 h; (c) $\mathrm{Pd}\left(\mathrm{PPh}_{3}\right)_{4}, 2 \mathrm{M}$ $\mathrm{K}_{2} \mathrm{CO}_{3}$, Toluene, $110^{\circ} \mathrm{C}, 24 \mathrm{~h}$.

2.1e Computational analysis: The vertical excitation energies and harmonic oscillator frequencies of PMI and PMIPd were computed using density functional theory (DFT) at the Becke's three parameter functional in combination with the Lee-Yang-Parr correlation functional (B3LYP) and 3-21G basis set. All the computations were performed using the Gaussian 09 Rev. A.02 and visualized using GaussView 5.0. ${ }^{41}$

2.1f Hirshfeld analysis ${ }^{42}$ : Important intermolecular interactions within the crystal structure of PMI and PMI-Pd were identified through Hirshfeld surface analysis using Crystal Explorer17. ${ }^{43}$ The Hirshfeld surface is defined as a set of points in $3 \mathrm{D}$ space where the ratio of promolecule and procrystal electron densities is equal to 0.5 . The exploration of intermolecular contacts is provided by mapping normalized contact distances $\left(d_{\text {norm }}\right)$, which is a function of the closest distance from the point to the nuclei interior $\left(\mathrm{d}_{\mathrm{i}}\right)$ and exterior $\left(d_{e}\right)$ to the surface as well as on the van der Waals radii $\left(r_{v d w}\right)$. 2D fingerprint which was generated by deriving from the Hirshfeld surface by plotting the fraction of points on the surface as the function of $\mathrm{d}_{\mathrm{i}}$ and $\mathrm{d}_{\mathrm{e}}$ which provide a visual summary of intermolecular contacts within the crystal.

\subsection{Synthesis and structural analysis}

Synthesis of PMI and PMI-Br were carried out following our previous reported procedures. ${ }^{27,44}$ The synthesized PMI$\mathrm{Br}$ was further reacted with tetrakis(triphenylphosphine) palladium( 0 ) and $2 \mathrm{M} \mathrm{K}_{2} \mathrm{CO}_{3}$ solution in toluene (under inert conditions) at $110{ }^{\circ} \mathrm{C}$ for $24 \mathrm{~h}$ to yield the title compound PMI-Pd (Scheme 1). Red single crystals of PMI-Pd (1:1, nhexane: chloroform) was obtained by slow evaporation of solvent from the homogenous solution at room temperature. Crystal structure of PMI is available with CCDC (Deposition No. 900321) and the crystallographic data for PMI-Pd derivative (1845450) is tabulated in Table S1, Supplementary Information (SI).

\subsection{Spectral characterization}

PMI-Pd: Yield: $10 \%$ (dark red solid); M.p. $>300{ }^{\circ} \mathrm{C} ;{ }^{1} \mathrm{H}$ NMR (500 MHz, $\left.\mathrm{CDCl}_{3}\right): \delta 8.51(\mathrm{~d}, J=8.1 \mathrm{~Hz}, 1 \mathrm{H}), 8.45$ (a)
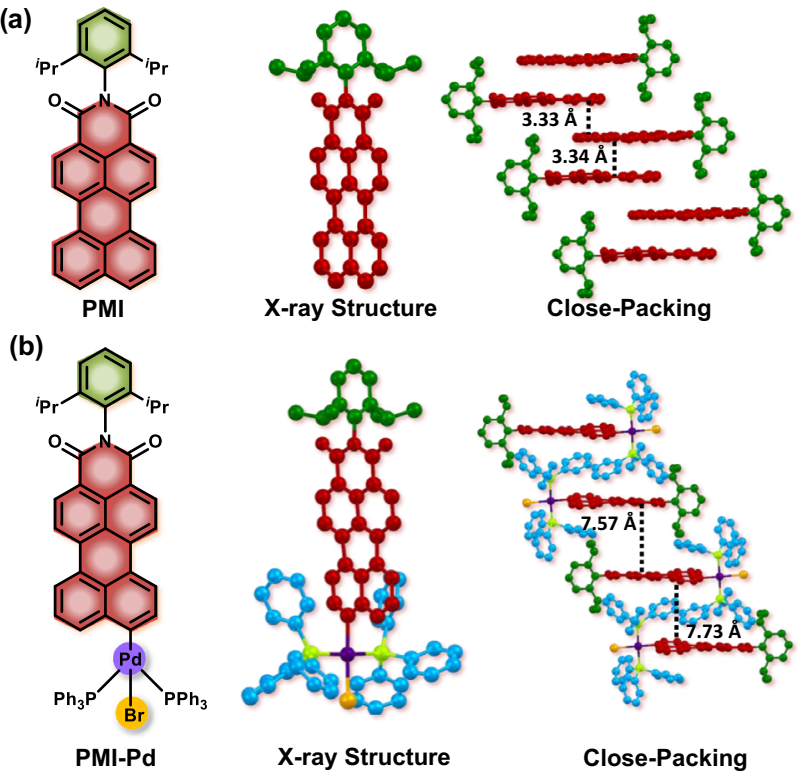

Figure 1. Molecular structure and close-packing of (a) PMI and (b) PMI-Pd. For clarity, the hydrogens have been omitted in the crystal structure and the close-packing.

$(\mathrm{d}, J=8.1 \mathrm{~Hz}, 2 \mathrm{H}), 8.18(\mathrm{~d}, J=8.2 \mathrm{~Hz}, 1 \mathrm{H}), 8.0-8.02$ (m, 2H), 7.44-7.47 (m, 12H), 7.37-7.41 (m, 3H), $7.25(\mathrm{~d}$, $J=7.85 \mathrm{~Hz}, 2 \mathrm{H}), 7.12-7.14(\mathrm{~m}, 8 \mathrm{H}), 7.05-7.08(\mathrm{~m}, 12 \mathrm{H})$, 2.66-2.70 (m, 2H), $1.11(\mathrm{~m}, 12 \mathrm{H})$; HRMS (ESI): m/z calculated for $\mathrm{C}_{70} \mathrm{H}_{56} \mathrm{BrNO}_{2} \mathrm{P}_{2} \mathrm{Pd}[\mathrm{M}+\mathrm{H}]^{+}:$1190.2083; Found : 1190.1963.

\section{Results and Discussion}

\subsection{Synthesis and structure}

The title compound PMI-Pd was synthesized by reacting $\mathrm{PMI}-\mathrm{Br}^{27,44}$ and tetrakis(triphenylphosphine)palladium (0) in toluene (with $2 \mathrm{M} \mathrm{K}_{2} \mathrm{CO}_{3}$ ) under inert conditions (Scheme 1, Figure 1). The precursor 9-bromoperylene monoimide (PMI-Br) was synthesized in accordance with our previous reported procedure by reacting perylene-3,4,9,10-tetracarboxylic anhydride (PTCDA) with 2,6-diisopropylaniline (yielding PMI) followed by successive bromination in the presence of elemental bromine (Scheme 1). ${ }^{27,44}$ Slow evaporation of a solution of PMI (chloroform) ${ }^{27}$ and PMI-Pd (in 1:1, $n$-hexane:chloroform) afforded decent quality crystals for X-ray diffraction (Figure 1). The molecular structure of PMI and PMI-Pd suggest a steric congestion mediated near-orthogonal $\left(\theta=85.8^{\circ}\right.$ and $86.8^{\circ}$ respectively) nature of the 2,6-diisopropylphenyl substituent at the imide region (Figure 1). The closepacking in PMI reveals the presence of two non-identical stacked PMI dimers with a distance of 3.33 and $3.34 \AA$. In contrast, the close-packing in PMI-Pd reveals the 
steric intervention of the flanking triphenylphosphine moiety between the two PMI cores lending a virtually negligible $\pi$-overlap (7.57 and $7.73 \AA$ ) between the adjacent PMI-Pd dimers (Figure 1). To get additional insights into the subtle intermolecular interactions guiding the close-packing, Hirshfeld surface analysis of PMI and PMI-Pd was carried out. Hirshfeld surface analysis and the corresponding 2D finger plot quantifies the $\%$ intermolecular interactions in the molecular assembly of PMI and PMI-Pd (Table S1, Supplementary Information). The $\rho(\% \mathrm{C} \cdot \bullet \mathrm{H} / \% \mathrm{C} \cdot \bullet \mathrm{C})$ value obtained from the Hirshfeld analysis suggest a $\beta$-motif and herringbone arrangement in the crystalline assembly (Figures S1-S2, Table S1, in Supplementary Information) of PMI and PMI-Pd, respectively.

\subsection{Steady-state spectroscopy}

To evaluate the preliminary photophysical features of PMI and PMI-Pd, steady-state UV-Vis absorption, fluorescence emission and lifetime measurements were carried out in chloroform (Figure 2). The UV-Vis absorption of PMI reveals a broad absorption ranging from 400 to $590 \mathrm{~nm}$ with peak centered at $520 \mathrm{~nm}$ (Table 2). The observed UV-Vis absorption of PMI in chloroform corresponds to a typical $\pi-\pi *$ (HOMO $\rightarrow$ LUMO) transition similar to the earlier literature reports (Figure 3, Table S2, in Supplementary Information). ${ }^{1,44}$ The fluorescence spectrum $\left(\lambda_{\mathrm{ex}}=480 \mathrm{~nm}\right)$ of PMI in chloroform reveal an intense emission $\left(\Phi_{\mathrm{f}}=0.86 \pm\right.$
0.02) with a narrow Stokes' shift and a characteristic vibronic pattern archetypally seen in rylene chromophores. ${ }^{45}$ The fluorescence lifetime measurement of PMI reveals a monoexponential decay with a lifetime of $4.85 \mathrm{~ns}$ suggesting a single decay pathway for the singlet excited state. The UV-Vis absorption spectrum of PMI-Pd complex reveals a red-shifted (20-30 nm) absorption centered at $540 \mathrm{~nm}(\mathrm{HOMO} \rightarrow$ LUMO) while still maintaining the characteristic vibronic features (Figure 3, Table S2, in Supplementary Information). The red-shifted UV-Vis absorption in PMI-Pd can be a result of the perturbation exerted by the $-\mathrm{Pd}\left(\mathrm{PPh}_{3}\right)_{2} \mathrm{Br}$ on the PMI core. ${ }^{1,46}$ A much higher perturbation is observed in the fluorescence spectrum $\left(\lambda_{\mathrm{ex}}=480 \mathrm{~nm}\right)$ of PMI-Pd in chloroform as compared to bare chromophore PMI. The emission spectrum of the PMI-Pd in chloroform reveals a $60 \mathrm{~nm}$ red-shift and a concomitant decrease in the fluorescence quantum yield $\left(\Phi_{\mathrm{f}}=0.38 \pm 0.02\right)$ as compared to PMI. Moreover, the picosecond timeresolved lifetime analysis of PMI-Pd in chloroform reveal a bi-exponential decay $\left(\tau_{\mathrm{f}}=1.64\right.$ and $\left.4 \mathrm{~ns}\right)$ of the fluorescence emission. The quenched emission and the bi-exponential decay of the fluorescence emission suggest an alternate pathway/phenomenon for the decay of the singlet excited state via incorporation of the Pd moiety in PMI-Pd. The photoexcited state characteristics of crystalline PMI and PMI-Pd differed slightly from the solution state properties (Figure S3 and Table S3, in Supplementary Information). The UVVis absorption of crystalline PMI $(300-650 \mathrm{~nm})$ and PMI-Pd (300-750) reveal red-shift as compared to that
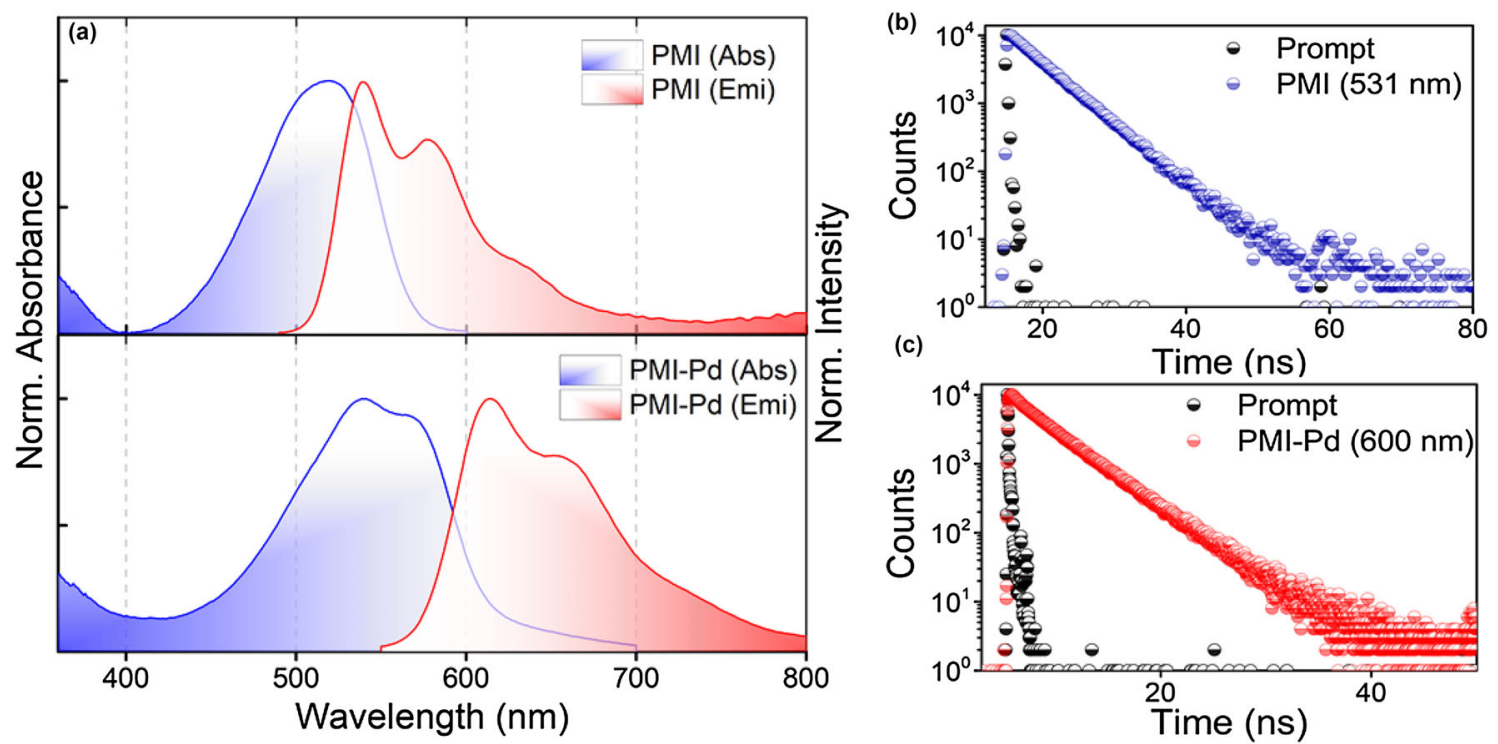

Figure 2. (a) Absorption and emission spectra $\left(\lambda_{e x}=480 \mathrm{~nm}\right.$ ) of PMI (top) and PMI-Pd (bottom); fluorescence decay profiles of (b) PMI $\left(\lambda_{\mathrm{ex}}=439 \mathrm{~nm}\right.$, pulse width $\left.<100 \mathrm{ps} ; \lambda_{\mathrm{emi}}=531 \mathrm{~nm}\right)$ and (c) PMI-Pd $\left(\lambda_{\mathrm{ex}}=478 \mathrm{~nm}\right.$, pulse width $\left.<90 \mathrm{ps} ; \lambda_{\mathrm{emi}}=600 \mathrm{~nm}\right)$. 
Table 2. Photophysical properties of PMI and PMI-Pd in $\mathrm{CHCl}_{3}$.

\begin{tabular}{lcccccc}
\hline Derivative & $\lambda_{\text {abs }}(\mathrm{nm})$ & $\lambda_{\mathrm{f}}(\mathrm{nm})$ & $\tau_{\mathrm{f}}[$ amplitude] $(\mathrm{ns})$ & $\Phi_{\mathrm{f}}$ & $\tau_{T}(\mathrm{~ns})$ & $\Phi_{T}$ \\
\hline PMI & 520 & $539,578,636$ & $4.85[100]$ & $0.86 \pm 0.02$ & $1.58 \pm 0.05 \mu \mathrm{s}$ & $0.08 \pm 0.005$ \\
PMI-Pd & 540 & $614,658,733$ & $1.64[10.5] 4[89.5]$ & $0.38 \pm 0.01$ & $0.90 \pm 0.03 \mu \mathrm{s}$ & $0.58 \pm 0.01$ \\
\hline
\end{tabular}

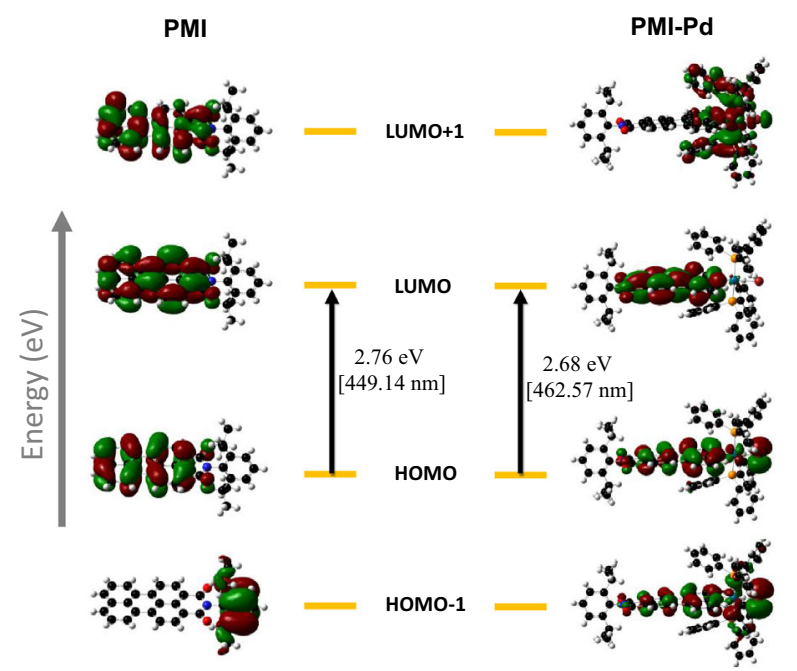

Figure 3. The frontier molecular orbital analysis (B3LYP/3-21G) of PMI (left) and PMI-Pd (right), respectively, carried out in Gaussian 09.

observed in chloroform solution. The emission spectra of crystalline PMI and PMI-Pd revealed a similar redshifted trend as that of UV-Vis absorption. Interestingly, the picosecond time-resolved lifetime analysis of crystalline PMI-Pd reveal a faster decay of the excited state as compared to crystalline PMI. The faster decay of the fluorescence lifetime in crystalline PMI-Pd suggests an alternate pathway (possibly triplet excited state) responsible for the faster decay of the singlet excited state in PMI-Pd, which is not present in crystalline PMI (Table 2).

\subsection{Transient absorption spectroscopy}

To further probe the photoexcited-state processes in PMI and PMI-Pd, ultrafast transient absorption spectroscopic measurements were carried out in monomeric chloroform solution. The fTA $\left(\lambda_{\mathrm{ex}}=400 \mathrm{~nm}\right)$ spectra of PMI and PMI-Pd reveal positive signal at $630-640 \mathrm{~nm}$, suggesting the presence of singlet excited state which does not completely decay within the given experimental window and is further supported by the time-resolved fluorescence lifetimes (Table 2, Figure S4, in Supplementary Information). Though the fTA spectra of PMI and PMI-Pd suggest the presence of the singlet excited state, the singlet-to-triplet conversion was not perceived.

To probe the existence of the triplet excited state, nTA spectroscopic measurements $\left(\lambda_{\mathrm{ex}}=355 \mathrm{~nm}\right)$ of PMI and PMI-Pd were carried out in a nitrogen purged chloroform solutions (Figure 4). The nTA spectra of PMI in chloroform reveal positive transient absorption at 500600 with a peak centered at $560 \mathrm{~nm}$ and which decay in a few microseconds timescale $\left(\tau_{T}=1.58 \pm 0.05 \mu \mathrm{s}\right.$, Figure $4 \mathrm{a})$. The long decay time of the transient species centered at $560 \mathrm{~nm}$ suggests the possibility of a triplet excited state. To confirm the existence of a triplet excited state, the nTA measurements of PMI were carried out in oxygen purged solutions. The triplet-triplet energy transfer (from ${ }^{3} \mathrm{PMI}-\mathrm{Pd}^{*}$ to the ground state (triplet) of oxygen) mediated decrease in the optical density and the fast decay of the $560 \mathrm{~nm}$ component in the oxygen purged solution confirms the presence of the triplet excited state of PMI. On the other hand, nTA measurements $\left(\lambda_{\mathrm{ex}}=355 \mathrm{~nm}\right)$ of PMI-Pd in chloroform reveals a transient signal at $620 \mathrm{~nm}$ with a lifetime of $0.90 \pm 0.05 \mu \mathrm{s}$ (Figure 4b). The minor variation in the position of the triplet excited state in PMI-Pd can be due to the difference in the triplet energy levels of PMI-Pd as compared to PMI, arising from a consequence of the incoming $-\mathrm{Pd}\left(\mathrm{PPh}_{3}\right)_{2} \mathrm{Br}$ (Figure 5). Upon oxygen purging, the positive transient absorption at $620 \mathrm{~nm}$ shows an apparent quenching, confirming the species to have a triplet origin. Interestingly, the triplet quantum yield $\left(\phi_{T}=0.58 \pm\right.$ $0.01 \mu \mathrm{s}$ ) of PMI-Pd in chloroform reveal a considerable increment as compared to PMI $\left(\phi_{T}=0.08 \pm\right.$ $0.005 \mu \mathrm{s})$. The apparent increase in the triplet yield in PMI-Pd can be a direct consequence of the spinorbit coupling mediated enhanced population of the triplet excited state and the reduced energy difference/near iso-energetic nature of the $S_{1}$ and $T_{2}$ energy levels (Figure 5). We believe that a tacit understanding of the spin-orbit coupling-mediated heavy-atom effect and the consequent enhancement in the triplet excited state of polyaromatic hydrocarbon can revive the design principles of novel organic materials for optoelectronic applications (Table S4, Supplementary Information). 

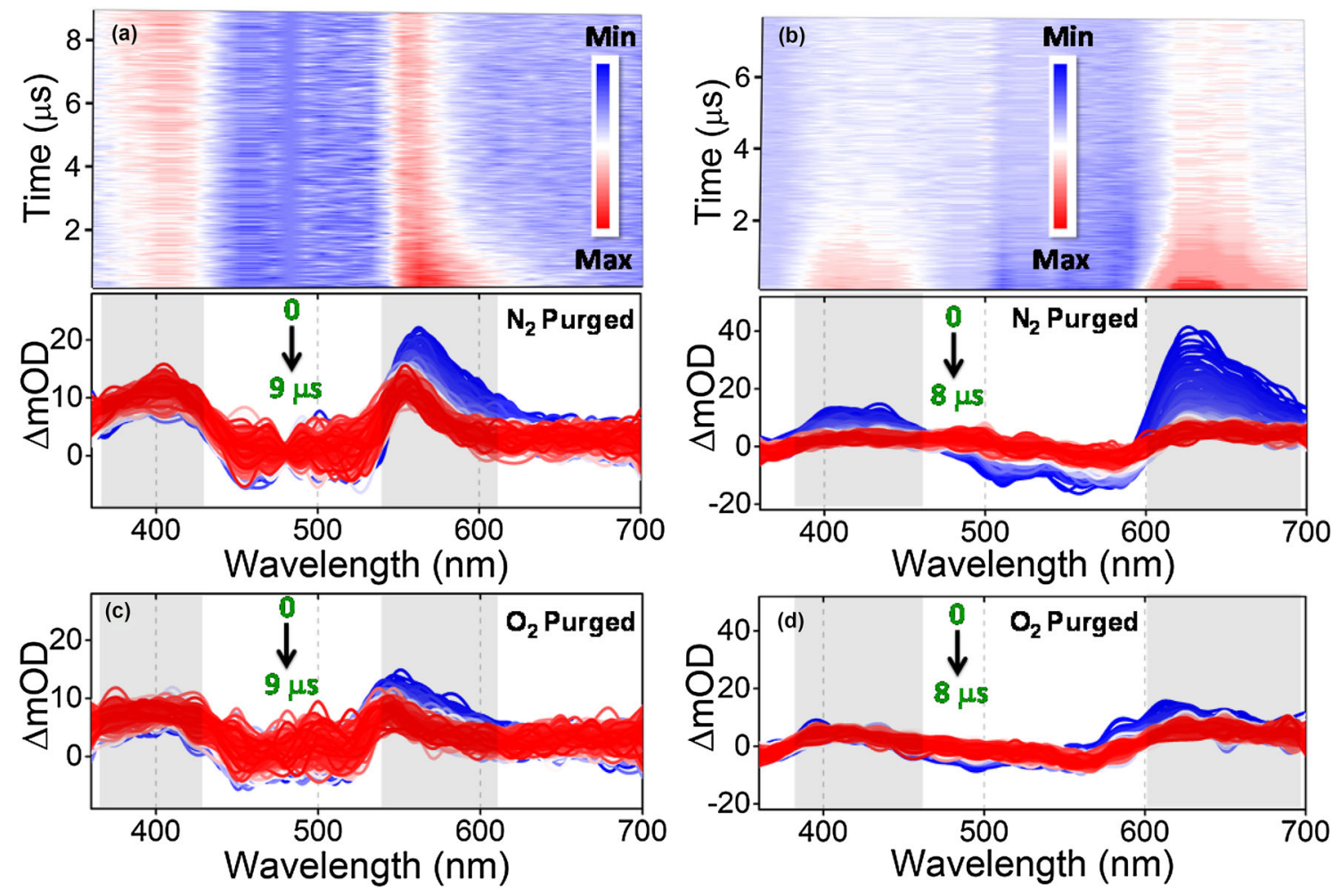

Figure 4. 2D plot (top) and nTA spectra (bottom, $\lambda_{e x}=355 \mathrm{~nm}$ ) of nitrogen purged solutions of (a) PMI and (b) PMI-Pd; nTA spectra ( $\lambda_{e x}=355 \mathrm{~nm}$ ) of oxygen purged solutions of (c) PMI and (d) PMI-Pd.

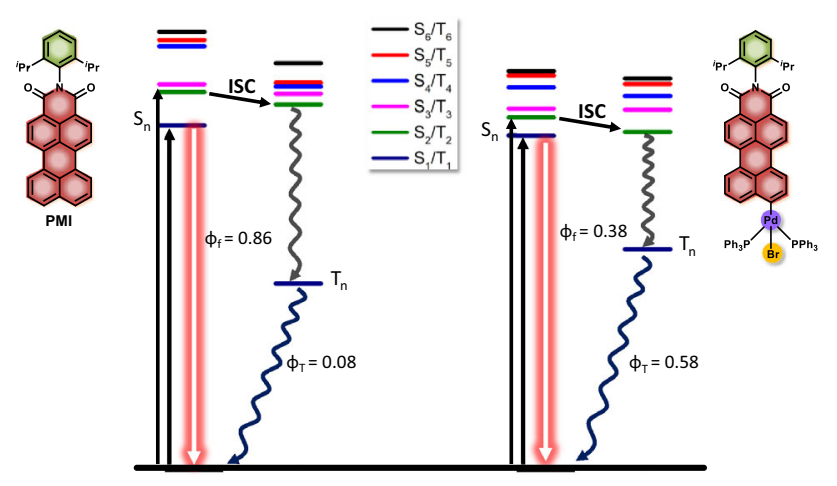

Figure 5. Jablonski diagram depicting the energy levels and the photophysics of PMI and PMI-Pd.

\section{Conclusions}

In summary, we report a novel arene-metal conjugate wherein the spin-orbit coupling mediated heavy atom effect conveys a higher triplet population in PMI-Pd. The arene-metal conjugate was synthesized via oxidative addition of $\mathrm{PMI}-\mathrm{Br}$ into $\mathrm{Pd}\left(\mathrm{PPh}_{3}\right)_{4}$ under inert conditions. The structural characterization of the model derivative PMI and PMI-Pd were carried out using single crystal X-ray diffraction and the close-packing analysis revealed the weak intermolecular interactions guiding the three-dimensional packing in the crystalline assembly. The steady-state UV-Vis absorption and emission spectra of PMI-Pd display an apparent red-shift when compared to the model derivative PMI, from a consequence of the effect exerted by the incoming $\mathrm{Pd}\left(\mathrm{PPh}_{3}\right)_{2} \mathrm{Br}$ group. The effect of the incoming Pd group is more pronounced in the photoexcited state processes of PMI-Pd. The nTA spectra of PMI-Pd exhibits an apparent increase in the triplet population from the incorporation of the heavy atom (Pd). The spin-orbit coupling-mediated heavy atom effect proposes a viable route to access the triplet excited state in polyaromatic chromophores possessing negligible triplet character. Enhancement of the triplet character in aromatic chromophores can have a progressive impact on the efficacy of such aromatic chromophores in solar light-to-energy conversion applications.

\section{Supplementary Information (SI)}

Crystallographic data for the structural analyses of PMI and PMI-Pd have been deposited with the Cambridge Crystallographic Data Centre bearing the CCDC Nos. 900321 and 1845450 , respectively. Copies of this information are available on request at free of charge from CCDC, Union Road, 
Cambridge, CB21EZ, UK (fax: +44-1223-336-033; e-mail: deposit@ccdc.ac.uk or http://www.ccdc.cam.ac.uk). Details of Hirshfeld analysis and close-packing (Figures S1-S2, Table 1), TD-DFT energy levels (Table S2) and fTA (Figure S4) analysis. Supplementary Information is available at www.ias.ac.in/chemsci.

\section{Acknowledgements}

M. H. acknowledges Kerala State Council for Science, Technology and Environment (KSCSTE) for the support of this work, 007/KSYSA-RG/2014/KSCSTE. The authors thank A. P. Andrews, IISER-TVM for the single crystal X-ray structure analyses. A.M.P., G.G., E.S. \& R.R. thank IISERTVM, and Department of Science and Technology (DST) INSPIRE, University Grant Commission (UGC) fellowships for the financial assistance.

\section{References}

1. Lentijo S, Miguel J A and Espinet P 2010 Highly Fluorescent Platinum(II) Organometallic Complexes of Perylene and Perylene Monoimide, with Pt $\sigma$-Bonded Directly to the Perylene Core Inorg. Chem. 499169

2. Langhals H 1995 Cyclic Carboxylic Imide Structures as Structure Elements of High Stability. Novel Developments in Perylene Dye Chemistry Heterocycles 40477

3. Zhan X, Facchetti A, Barlow S, Marks T J, Ratner M A, Wasielewski M R and Marder S R 2011 Rylene and Related Diimides for Organic Electronics Adv. Mater. 23 268

4. Gao X and Hu Y 2014 Development of n-type organic semiconductors for thin film transistors: a viewpoint of molecular design J. Mater. Chem. C 23099

5. Chen L and Henrike W 2012 Perylene Imides for Organic Photovoltaics: Yesterday, Today, and Tomorrow $A d v$. Mater. 24613

6. Kelley R F, Shin W S, Rybtchinski B, Sinks L E and Wasielewski M R 2007 Photoinitiated Charge Transport in Supramolecular Assemblies of a 1,7,N,N'-Tetrakis(zinc porphyrin)-perylene-3,4:9,10bis(dicarboximide) J. Am. Chem. Soc. 1293173

7. Bullock J E, Carmieli R, Mickley S M, Vura-Weis J and Wasielewski M R 2009 Photoinitiated Charge Transport through $\pi$-Stacked Electron Conduits in Supramolecular Ordered Assemblies of Donor-Acceptor Triads J. Am. Chem. Soc. 13111919

8. Prodi A, Chiorboli C, Scandola F, Iengo E, Alessio E, Dobrawa R and Würthner F 2005 WavelengthDependent Electron and Energy Transfer Pathways in a Side-to-Face Ruthenium Porphyrin/Perylene Bisimide Assembly J. Am. Chem. Soc. 1271454

9. Rajaram S, Shivanna R, Kandappa S K and Narayan K S 2012 Nonplanar Perylene Diimides as Potential Alternatives to Fullerenes in Organic Solar Cells J. Phys. Chem. Lett. 32405

10. Nielsen C B, Holliday S, Chen H-Y, Cryer S J and McCulloch I 2015 Non-Fullerene Electron Acceptors for Use in Organic Solar Cells Acc. Chem. Res. 482803
11. Sharma P, Damien D, Nagarajan K, Shaijumon M M and Hariharan M 2013 Perylene-polyimide-Based Organic Electrode Materials for Rechargeable Lithium Batteries J. Phys. Chem. Lett. 43192

12. Banda H, Damien D, Nagarajan K, Hariharan M and Shaijumon M M 2015 A polyimide based all-organic sodium ion battery J. Mater. Chem. A 310453

13. Banda H, Damien D, Nagarajan K, Hariharan M and Shaijumon M M 2017 Sodium-Ion Batteries: Twisted Perylene Diimides with Tunable Redox Properties for Organic Sodium-Ion Batteries (Adv. Energy Mater. 20/2017) Adv. Energy Mater. 7. https://doi.org/10.1002/ aenm.201770112

14. Nagarajan K, Mallia A R, Reddy V S and Hariharan M 2016 Access to Triplet Excited State in Core-Twisted Perylenediimide J. Phys. Chem. C 1208443

15. Zhihua X and Bin H 2008 Photovoltaic Processes of Singlet and Triplet Excited States in Organic Solar Cells $A d v$. Funct. Mater. 182611

16. Rao A, Chow P C Y, Gélinas S, Schlenker C W, Li C-Z, Yip H-L, Jen A K Y, Ginger D S and Friend R H 2013 The role of spin in the kinetic control of recombination in organic photovoltaics Nature $\mathbf{5 0 0} 435$

17. Ford W E and Kamat P V 1987 Photochemistry of 3,4,9,10-perylenetetracarboxylic dianhydride dyes. 3 . Singlet and triplet excited-state properties of the bis(2,5di-tert-butylphenyl)imide derivative J. Phys. Chem. 91 6373

18. Tilley A J, Pensack R D, Lee T S, Djukic B, Scholes G D and Seferos D S 2014 Ultrafast Triplet Formation in Thionated Perylene Diimides J. Phys. Chem. C 118 9996

19. Vagnini M T, Smeigh A L, Blakemore J D, Eaton S W, Schley N D, D'Souza F, Crabtree R H, Brudvig G W, Co D T and Wasielewski M R 2012 Ultrafast photodriven intramolecular electron transfer from an iridium-based water-oxidation catalyst to perylene diimide derivatives Proc. Natl. Acad. Sci. U. S. A. 10915651

20. Rachford A A, Goeb S and Castellano F N 2008 Accessing the Triplet Excited State in Perylenediimides J. Am. Chem. Soc. 1302766

21. Marcus S, Andreas S and Frank W 2015 Near-IR Phosphorescent Ruthenium(II) and Iridium(III) Perylene Bisimide Metal Complexes Angew. Chem. 1271590

22. Smith M B and Michl J 2010 Singlet Fission Chem. Rev. 1106891

23. Eaton S W, Shoer L E, Karlen S D, Dyar S M, Margulies E A, Veldkamp B S, Ramanan C, Hartzler D A, Savikhin S, Marks T J and Wasielewski M R 2013 Singlet Exciton Fission in Polycrystalline Thin Films of a Slip-Stacked Perylenediimide J. Am. Chem. Soc. 13514701

24. Mallia A R, Salini P S and Hariharan M 2015 Nonparallel Stacks of Donor and Acceptor Chromophores Evade Geminate Charge Recombination J. Am. Chem. Soc. 137 15604

25. Cheriya R T, Mallia A R and Hariharan M 2014 Light Harvesting Vesicular Donor-Acceptor Scaffold Limits the Rate of Charge Recombination in the Presence of an Electron Donor Energy Environ. Sci. 71661

26. Dance Z E X, Mickley S M, Wilson T M, Ricks A B, Scott A M, Ratner M A and Wasielewski M R 2008 Intersystem Crossing Mediated by Photoinduced 
Intramolecular Charge Transfer: Julolidine-Anthracene Molecules with Perpendicular $\pi$ Systems J. Phys. Chem. A 1124194

27. Cheriya R T, Nagarajan K and Hariharan M 2013 SingleComponent Organic Light-Harvesting Red Luminescent Crystal J. Phys. Chem. C 1173240

28. Rajagopal S K, Philip A M, Nagarajan K and Hariharan M 2014 Progressive Acylation of Pyrene Engineers Solid

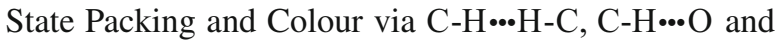
$\pi-\pi$ Interactions Chem. Commun. 508644

29. Nagarajan K, Gopan G, Cheriya R T and Hariharan M 2017 Long alkyl side-chains impede exciton interaction in organic light harvesting crystals Chem. Commun. 53 7409

30. Philip A M, Mallia A R and Hariharan M 2016 Prolonged Charge Separated States in Twisted Stacks of All-Carbon Donor and Acceptor Chromophores J. Phys. Chem. Lett. 74751

31. Mallia A R, Philip A M, Bhat V and Hariharan M 2017 Persistent Charge-Separated States in Self-Assembled Twisted Nonsymmetric Donor-Acceptor Triads J. Phys. Chem. C 1214765

32. Philip A M, Kuriakose F and Hariharan M 2017 Unsolicited Photoexcited-State Pathways Relegate the Long-Lived Charge Separation in Self-Assembled Nucleobase-Arene Conjugate J. Phys. Chem. C 121 23259

33. Nagarajan K, Mallia A R, Muraleedharan K and Hariharan M 2017 Enhanced intersystem crossing in coretwisted aromatics Chem. Sci. 81776

34. Lakowicz J R 2007 In Principles of Fluorescence Spectroscopy (Springer: NY, USA) p. 54

35. Sheldrick G 2008 A Short History of SHELX Acta Cryst. A 64112

36. Farrugia L 1999 WinGX Suite for Small-Molecule Single-Crystal Crystallography J. Appl. Cryst. 32837

37. Macrae C F, Bruno I J, Chisholm J A, Edgington P R, McCabe P, Pidcock E, Rodriguez-Monge L, Taylor R, van de Streek J and Wood P A 2008 Mercury CSD 2.0 New Features for the Visualization and Investigation of Crystal Structures J. Appl. Cryst. 41466

38. Bruno I J, Cole J C, Edgington P R, Kessler M, Macrae C F, McCabe P, Pearson J and Taylor R 2002 New Software for Searching the Cambridge Structural Database and Visualizing Crystal Structures Acta Cryst. B 58389
39. Wu Y-L, Brown K E and Wasielewski M R 2013 Extending Photoinduced Charge Separation Lifetimes by Using Supramolecular Design: GuaninePerylenediimide G-Quadruplex J. Am. Chem. Soc. 135 13322

40. Rajagopal S K, Mallia A R and Hariharan M 2017 Enhanced intersystem crossing in carbonylpyrenes Phys. Chem. Chem. Phys. 1928225

41. Frisch M J, Trucks G W, Schlegel H B, Scuseria G E, Robb M A, Cheeseman J R, Scalmani G, Barone V, Mennucci B, Petersson G A, Nakatsuji H, Caricato M, Li X, Hratchian H P, Izmaylov A F, Bloino J, Zheng G, Sonnenberg J L, Hada M, Ehara M, Toyota K, Fukuda R, Hasegawa J, Ishida M, Nakajima T, Honda Y, Kitao O, Nakai H, Vreven T, Montgomery Jr. J A, Peralta J E, Ogliaro F, Bearpark M J, Heyd J, Brothers E N, Kudin K N, Staroverov V N, Kobayashi R, Normand J, Raghavachari K, Rendell A P, Burant J C, Iyengar S S, Tomasi J, Cossi M, Rega N, Millam N J, Klene M, Knox J E, Cross J B, Bakken V, Adamo C, Jaramillo J, Gomperts R, Stratmann R E, Yazyev O, Austin A J, Cammi R, Pomelli C, Ochterski J W, Martin R L, Morokuma K, Zakrzewski V G, Voth G A, Salvador P, Dannenberg J J, Dapprich S, Daniels A D, Farkas Ö, Foresman J B, Ortiz J V, Cioslowski J and Fox D J, Gaussian 09 Rev. A.02, Gaussian, Inc., Wallingford CT, USA, 2009

42. Spackman M A and Jayatilaka D 2009 Hirshfeld Surface Analysis CrystEngComm 1119

43. Wolff S K, Grimwood D J, McKinnon J J, Turner M J, Jayatilaka D and Spackman M A 2012 CrystalExplorer (Version 3.1), University of Western Australia

44. Cheriya R T, Joy J, Alex A P, Shaji A and Hariharan M 2012 Energy Transfer in Near-Orthogonally Arranged Chromophores Separated through a Single Bond J. Phys. Chem. C 11612489

45. Bullock J E, Vagnini M T, Ramanan C, Co D T, Wilson T M, Dicke J W, Marks T J and Wasielewski M R 2010 Photophysics and Redox Properties of Rylene Imide and Diimide Dyes Alkylated Ortho to the Imide Groups $J$. Phys. Chem. B 1141794

46. Weissman H, Shirman E, Ben-Moshe T, Cohen R, Leitus G, Shimon L J W and Rybtchinski B 2007 Palladium Complexes of Perylene Diimides: Strong Fluorescence Despite Direct Attachment of Late Transition Metals to Organic Dyes Inorg. Chem. 464790 